\title{
[ 298 ]
}

X. A Fiffory of a large Tumour, in the Regions of the Abdomen, containing Hair. By John Warren, Efg. F. A. A. and M. S. and Profeflor of Anatomy and Surgery in the Univerfity of Cambridge. - From the Memoirs of the American Academy of Arts and Sciences, Vol. I. 4to. Bofton, 1785 .

A $\mathrm{N}$ averfion to the making of large inciA fions into fuch tumours as have appeared to have been feated within the cavity of the abdomen, has perhaps often been the reafon why thofe of them which have happened to contain a fubftance lefs fluid than pus have either induced a hectic, from a copious abforption of the thinner and more acrid parts, or have fpeedily been followed by a fatal termination. The following hiftory may in fome meafure evince the fafety of fuch large and free openings in cafes of this kind; but the facts contained in it may alfo admit of an application to the purpofe of explaining sertain phenomena in the animal oconomy.

The production of hair in the human body, though it has often been the fubject of accurate examination, and ingenious fpeculation, has perhaps never yet been fatisfactorily accaunted for; or, to fay the leaft, the folution is ftill deftitute 


\section{[ 299 ]}

deftitute of that fupport and conviction which, in moft other phyfiological inquiries, have fo happily been attained.

Admitting the pofition, that many, if not all the interior parts of the body are furnifhed with the neceffary fluids for the growth of this fubftance, an accurate attention to the circumftances under which it is really produced, and to the nature of the parts in which it is moft frequently found, muft undoubtedly afrord very confiderable light on the fubject; and from a large number of fuch facts, carefully and judicioufly collected, it is not improbable that every doubt and difficulty attending the invertigation may be entirely remowed.

Z- $-\mathrm{H}-$ - a negro woman, about thirty-two years of age, early in the year $7^{8} 3$ applied for medical affiftance in a cafe of a fwelling in the abdomen, which had become extremely painful, and which began to be attended with very threatening fymptoms. On examination, a very large tumour was found feated chiefly on the left fide, occupying the whole fpace between the left os ilium and the left inferior ribs, and extending over to the right of the umbilical region, pointing a little to the left of the navel, confiderably hard, and

$$
\text { Qq. } 2 \text { extremely }
$$




\section{[ 300 ]}

extremely fenfible. Upon inquiry into the oris gin of the tumour, it appeared, that the patient had firft complained of pain in the left groin, and a general enlargement of the abdomen, irnmediately after delivery of her third child: this gradually increafed after two fucceffive labours, and fince the birth of her laft child, now about twelve years of ago, had been almoft conftantly painful, though by no means in a very diftreffing degree, until about three weeks prior to her application for advice. At this period her complaints were greatly exafperated, in confequence of catching cold at the time of the catamenial evacuation, by which a total fuppreffion was induced. The common difcutient topical applications were immediately made ufe of; the ufual methods were employed to renew the difcharge; but all to no purpofe. The fwelling conftantly increafed for about three weeks, when an evident tendency to fup: puration being perceived, the method of cure was immediately altered from a difcutient to a fuppurative procefs. In about two weeks a fluctuation was perceptible, and at the end of two more an opening into the cavity of the tumour was determined upon: 


\section{[ 301 ]}

An extenfive incifion was accordingly made through the rectus mufcle, at a fufficient diffance from the ufual courfe of the epigaftric artery to avoid all danger of wounding it, and about a pint of watery matter immediately iffued through the orifice; after which about the fame quantity of pure pus was difcharged.

On introducing two or three fingers into the cavity, a quantity of foft fubftance was felt within it, much about the confiftency of foft fope. I immediately made ufe of a table fpoon as the moft convenient inftrument that could be readily procured for extracting it, and about a pound of it was at this time obtained; after which a degree of faintnefs began to enfue, the wound was dreffed, and the pafient placed in her bed in a proper fituation for admitting of a free difcharge of any fluid that might ftill be retained.

At the three or four fucceeding dreffings a portion of the fame fubftance was taken out, till the whole being extracted, it amounted to the quantity of about four pounds.

At each dreffing the matter was particularly examined, and was found to contain a large quantity of fhort hair or wool, about three quarters of an inch long, uniformly mixed with 


\section{[ 302 ]}

with it, as is feen in the fpecimen herewith prefented for the infpection of the Academy.

In each hair was difcoverable by the naked eye a bulbous root, and a pointed extremity, both perfectly fimilar to what is feen in an entire hair produced naturally in other parts of the body. After the removal of the whole fubftance, the hand was paffed into and round the cavity in fearch of bone, or any other foreign body which might be contained within it; but though fome of the gentlemen prefent, on fuppofition of an extra-uterine fotus, expected to have found the former, yet nothing of either could be felt, though every part was fairly ac: ceffible. From this examination it evidently appeared that the matter extracted had been contained in a fac which firmly adhered to the peritoneum, a circumftance, I believe, generally attendant on fuppurations in the vifcera of the abdomen, as the natural confequence of previous inflammation,

On being expofed to the heat of the fire in an open veffel, it emitted a ftrong urinous fmell, and was attended in other refpects with moft of the appearances ufually exhibited in the broiling of animal fubftances. The action of flame produced a fmart and continued de-

crepitation 


\section{[ $3 \circ 3]$}

crepitation of the falt contained in it, until the whole was reduced to a fimple coal; but no figns of inflammability, or the prefence of any oily fubftance, were perceptible. When boiled, the water made ufe of in the procefs was very little changed as to its fenfible properties; but after ftanding fome time in a veffel to cool, it depofited a fediment which was fufpected to be an alkaline falt, and which accordingly readily fermented with the vitriolic acid.

The patient, from the ufe of the bark, fuperficial dreffings, and a reftorative diet, was, in about three months, enabled to enter upon her ufual employment, which was bufinefs of the moft laborious kind. She had during her illnefs been much reduced, and for fome time continued in an emaciated fate, yet the now enjoys perfect health, and has become moderately corpulent. The catamenial evacuation has been regularly performed; but no figns of pregnancy have ever appeared, though, before her ficknefs, the had borne children uncommonly faft.

Many of the practitioners in the town of Bofton were called in to vifit the patient, and various were the conjectures upon the nature of the cafe. The abfence of all the ufual figns 


\section{[ 304. ]}

of pregnancy, except at thofe periods which regularly preceded the refpective deliveries above méntioned, is a frong argument againft the hypothefis of an extra-uterine foetus; and it thould feem by no means admiffible that the bones fhould have been fo perfectly diffolved as to have formed with the mufcular, and other foft parts of a foctus, one uniform and apparently homogeneous mafs of matter. Are we not authorized, from the general complexion of the care, particularly from the pain in the groin of the affected fide, to pronounce the ovarium to have been the fuffering part? The attachment of the ligamentum rotundum of the uterus to the adipofe fubftance in the groin, feems to point out, either the uterus, or fome other part connected with it, as the feat of the diforder.

A difeafed ovarium may eafily be conceived to acquire a fize too great to admit of its being contained in the pelvis, and from its elevation in the abdominal region, the uterus itfelf might alfo be raifed, and a diftention of the ligament thereby be produced. But it is farther probable, that from an immediate adhefion of the ovarium to the neighbouring part of the uterus, the inflammation with which thofe parts might 


\section{[ 305 ]}

be affeeted would extend to the ligament itfelf; the former caufe operating in conjunction with this, would fufficiently account for the pain in the groin of the affected fide; and the application of this reafoning in the above inftance, together with the other facts contained in the hiftory, might enable us, without much difficulty, to form a pretty fure diagnofis of the difeafe.

XI. An Account of the Horn Diftemper in Cattle, with Obfervations on that Difeafe. By the Hon. Cotton Tufts, M.D. F.A.A. and M.S. In a Letter to the Rev. Jofeph Willard, Cor. Sec. A. A. - From the Memoirs of the American Academy of Aris and Sciences, Vol. I. 4to. Bofton, $17^{8} 5$.

- EASTS of the foreft, guided by the dic1. tates of nature, and uncontrolled by man in their food, air, exercife, and reft, are feldom affected with any difeafe; whilit, in almoft all countries, the domeftic kind, that are more immediately under the government of man, are fubject to a variety.

Scarcely an inftance in this country of reigning ficknefs among tame or wild beafts has Vol.VII. Part III. Rr been 